\title{
A Percepção do Turismo por Parte da Comunidade Local e dos Turistas no Município de Cajueiro da Praia - PI
}

\section{The Perceptions of Tourism by the local community and tourists in the city of Cajueiro da Praia - PI}

Stella Maria Sousa Carvalho ${ }^{1}$

\section{Resumo}

O turismo é uma atividade que pode ser uma alternativa para diversificar economias, gerar empregos e renda, promover a preservação ambiental e melhorar a qualidade de vida de localidades que têm potencial para tal. Entretanto, é fundamental que a comunidade receptora participe do processo de desenvolvimento turístico para que os seus benefícios não se limitem à poucos. Assim, este artigo mostra a percepção dos moradores do município de Cajueiro da Praia - PI, englobando a sede municipal e os povoados da orla marítima, bem como a percepção dos turistas que o visitam. A metodologia deste trabalho foi baseada em uma pesquisa de campo com amostras do tipo não probabilísticas, e consistiu na aplicação de questionários com os moradores de cada localidade e com os turistas que estavam no município, durante os períodos de aplicação dos mesmos. Assim, percebeu-se, então, que a comunidade do município de Cajueiro da Praia aceita e quer que o turismo seja desenvolvido, porém grande parte dos moradores não tem consciência da natureza do turismo e dos seus impactos. E em relação à percepção dos turistas, a sua maioria tem uma boa impressão do município e pretende voltar outras vezes, o que leva a continuidade do desenvolvimento turístico local.

Palavras-chave: percepção; impactos do turismo; potencialidades; limitações.

\begin{abstract}
Tourism is an activity that can be an alternative to diversify economies, create jobs and income, promote environmental conservation and improve life quality on potential locations. However, it is essential that the host community participate in the process of tourism development so that their benefits are not limited to the few. Thus, this article shows the Cajueiro da Praia - PI residents' perception, covering the municipal headquarters and the villages along the coast, as well as tourists' perception. The methodology of this study was based on field research with samples of the non-probability, and consisted of questionnaires with the local residents and tourists who were in the city during the periods of application. Thus, it was noted that the community council of Cajueiro da Praia wants and accepts

\footnotetext{
${ }^{1}$ Bacharel em Turismo pela Universidade Estadual do Piaú - UESPI. Mestre em Desenvolvimento e Meio Ambiente pela Universidade Federal do Piauí - UFPI. Professora efetiva do curso Guia de Turismo do Instituto Federal do Piauí - IFPI. Email: carvalhosms@gmail.com.
} 
tourism development, but most residents are unaware of the nature of tourism and its impacts. Regarding tourists' perception, most of them have a good impression of the city and wants to come back sometimes, which leads to continuity of local tourism development.

Keywords: perception; tourism impact; potential; limitations.

\section{Introdução}

O turismo é uma importante atividade econômica, que tem crescido bastante nos últimos anos, e pode proporcionar inúmeros efeitos positivos para localidades com potencial para desenvolvê-lo. Entretanto, desenvolver o turismo não é trabalho simples para os gestores públicos, pois exige planejamento e participação de todos os envolvidos, direta e indiretamente, no processo.

Para tanto, é necessário que todos tenham conhecimento dos impactos que o turismo pode provocar, tanto positivos como negativos, e aceitem que a atividade turística seja desenvolvida. Neste sentido, identificar a percepção do turismo, tanto por parte dos moradores quanto por parte dos turistas, é fundamental para o sucesso de qualquer plano de desenvolvimento turístico.

Segundo Oliveira (2006, p. 3),

a percepção das pessoas, sobre determinado assunto, é sempre carregada de uma visão própria de cada indivíduo, formada a partir de variáveis como meio social, história de vida, nível de escolaridade, religião, atividade econômica, entre outros. Conseqüentemente, cada indivíduo percebe o mundo qualitativa, efetiva e valorativamente, e é a partir dessa percepção que define seu modo de relação com a sociedade.

Desta maneira, apesar da percepção ser individual, ao se analisar esta impressão de uma população, de modo geral, pode ser considerado o entendimento comum, ou seja, a vontade da maioria.

Em relação à percepção dos turistas sobre um determinado destino turístico, Walter (apud CAMPOS, 2006, p. 5) afirma que a 
satisfação ou insatisfação em relação a uma determinada viagem depende, é claro, da percepção do viajante. Expectativa, experiência e memória têm a ver com a realidade da mente, inatingíveis e imateriais, que não deixam os porquês das viagens visíveis, palpáveis ou verificáveis nem as razões pelas quais uma mesma viagem pode ser vivida de tantas maneiras diferentes.

A percepção dos moradores sobre o turismo é necessária para compreender como eles vêem a atividade, e como estão inseridos na mesma. Se a comunidade local não estiver inserida e nem aceitar o desenvolvimento turístico local, ele estará fadado ao fracasso, pois os moradores podem rejeitar o turismo e tratar mal os visitantes, afetando diretamente o desenvolvimento da atividade.

Neste sentido, este trabalho, parte integrante da dissertação de Mestrado em Desenvolvimento e Meio Ambiente, da Universidade Federal do Piauí, buscou analisar a percepção dos turistas e dos moradores do município de Cajueiro da Praia - PI, englobando a sede municipal e os povoados da orla marítima - Barra Grande, Barrinha e Morro Branco.

\section{O Município de Cajueiro da Praia - PI}

O município de Cajueiro da Praia foi criado pelo desmembramento de $281,75 \mathrm{~km}^{2}$ do território do município de Luís Correia, Piauí, através do Decreto-Lei 4.810 de 27 de dezembro de 1995. Está localizado no extremo norte do Estado, aproximadamente $400 \mathrm{~km}$ da capital do Piauí, Teresina.

De acordo com dados do Sistema de Informação de Atenção Básica - SIAB, da Prefeitura Municipal de Cajueiro da Praia, através do cadastro de famílias para o Programa Saúde da Família - PSF, obtidos por meio de observação direta, até maio de 2009, a população do município era de 7.047 habitantes.

Cajueiro da Praia faz parte do Pólo Costa do Delta, juntamente com Luís Correia, Parnaíba, Ilha Grande e Buriti dos Lopes, uma das regiões turísticas do Estado, de acordo com a política estadual de turismo, que dividiu o Piauí em sete pólos com potencial para desenvolvimento da atividade. Os Pólos, com o respectivo atrativo principal, são os seguintes: Pólo Costa do Delta 
(Delta do Rio Parnaíba), Pólo Aventura e Mistério (Parque Nacional Sete Cidades), Pólo das Águas (Cachoeira do Urubu), Pólo Teresina (cidade de Teresina), Pólo Histórico Cultural (cidade de Oeiras), Pólo das Origens (Parque Nacional Serra da Capivara) e Pólo das Nascentes (Parque Estadual das Nascentes) (PIAUÍ, 2009).

Desde 2005, o Pólo Costa do Delta está inserido em um projeto de integração desenvolvido pelo Serviço Brasileiro de Apoio às Micro e Pequenas Empresas - SEBRAE, conhecido como Rota das Emoções, cujo objetivo é desenvolver produtos e roteiros turísticos de integração dos destinos de Jericoacoara (CE), Delta do Parnaíba (PI) e Lençóis Maranhenses (MA) através da capacitação dos empreendedores locais e da identificação às potencialidades turísticas dos municípios envolvidos.

Em julho de 2009, o roteiro Rota das Emoções recebeu do Ministério do Turismo - MTUR o prêmio Troféu Roteiros do Brasil, uma iniciativa do Programa de Regionalização do Turismo, na categoria Roteiro Turístico, como um exemplo de sucesso no desenvolvimento do turismo em regiões integradas. O Projeto concorreu com mais de 90 destinos turísticos do país, e ficou em $1^{\circ}$ lugar nesta categoria. Deste modo, com este prêmio a região ganhou uma maior visibilidade no mercado turístico, o que pode levar um aumento da demanda turística local, beneficiando as localidades pertencentes ao roteiro (BRASIL, 2009).

Em relação aos aspectos ambientais, de acordo com Cavalcanti (2000), o clima do município de Cajueiro da Praia, classificado segundo a metodologia de Thornthwaite, pode ser denominado como sub-úmido, com moderado excesso de água no inverno, tipo megatérmico. Em relação aos ventos, assim como em toda costa litorânea do Piauí, sofrem mudanças de direção, intensidade e velocidade durante o período diurno e noturno, ao longo do ano. E ainda conforme o autor, as máximas de velocidade dos ventos ocorrem nos meses de agosto, setembro e outubro, chegando a valor superior a $7 \mathrm{~m} / \mathrm{s}$.

O clima do município é propício para o desenvolvimento do turismo, pois pode atrair turistas de outros Estados que estão em busca de climas mais quentes, porém nos períodos de chuva pode ser um fator limitante. Os ventos alísios, por serem bastante intensos, também favorecem a prática de esportes náuticos no município, como o kitesurf, que é bastante praticado na região. 
Geologicamente, o município de Cajueiro da Praia, assim como a área litorânea do Estado, está inserido na bacia sedimentar do Parnaíba, com terrenos de formações recentes, compostos essencialmente de sedimentos quaternários inconsolidados, submetidos às ações de acumulação marinha, eólica, fluvial e flúvio-marinha. O seu solo é formado, principalmente de associações de areias quartzosas marinhas e continentais, juntamente com os mangues, que fazem parte de um ecossistema costeiro de transição entre os ambientes marinhos e terrestres. Em algumas faixas de praias, há a presença de rochas de praia (arenitos) situadas abaixo da linha de alta maré (PIAUÍ, 1996).

Em relação a aspectos hidrográficos em Cajueiro da Praia destacam-se quatro rios principais: os rios Timonha e Ubatuba, do lado leste, e os rios Camurupim e Cardoso, do lado oeste. Há, também, várias lagoas, alimentadas por regimes pluvial, fluvial e freático, como a Lagoa da Santana e Lagoa dos Pemas, porém sem utilização turística.

O município de Cajueiro da Praia, outros três municípios litorâneos do Piauí (Luís Correia, Parnaíba e Ilha Grande), dois do Ceará (Barroquinha e Chaval) e um município do Maranhão (Tutóia) fazem parte de uma unidade de conservação da categoria de uso direto (sustentável), do tipo Área de Proteção Ambiental - APA, a APA do Delta do Parnaíba, sob responsabilidade do Instituto Chico Mendes de Conservação da Biodiversidade - ICMBio. A APA do Delta do Parnaíba tem por objetivos principais: proteger os estuários dos rios Parnaíba, Timonha e Ubatuba, com sua fauna, flora e complexo dunar; proteger remanescentes de mata aluvial; proteger os recursos hídricos; melhorar a qualidade de vida das populações residentes, mediante orientação e disciplina das atividades econômicas locais; fomentar o turismo ecológico e a educação ambiental; preservar as culturas e as tradições locais.

A vegetação de Cajueiro da Praia é caracterizada como de transição restinga/mangue, com a presença de muitos elementos de caatinga, como as carnaubeiras (Copernicia prunifera). Os manguezais, com predomínio das espécies mangue-vermelho (Rhizophora mangle) nas margens dos cursos d'água, e as espécies mangue-manso (Laguncularia racemosa) e manguesiriba (Avicennia germinans) são presentes mais no interior do manguezal (PIAUÍ, 1996). 
Em relação à fauna, Baptista (2004) afirma que o município, por estar localizado numa área de plataforma continental, tem grande diversidade de espécies marinhas e terrestres, como: peixes coró-roxo (Conodon nobilis) e carapitanga (Lutianus jocu); répteis: tartaruga verde (Chelonia mydas) e jibóia (Boa constrictor); aves: garça azul (Florida caerulea) e queroquero (Valenus chilenses); e mamíferos: peixe-boi marinho (Trichechus manatus manatus).

Sobre atrativos e potenciais turísticos do município existem vários, alguns que realmente atraem visitantes, como as praias do povoado Barra Grande e a possibilidade de fazer passeios ecológicos que unem ecoturismo e turismo de aventura no mesmo povoado, e outros que não passam de potenciais, pois ainda não atraem visitantes, como as lagoas, e as praias dos outros povoados. Há também a possibilidade de observação da vida animal em habitat natural, como o peixe-boi, na sede municipal.

Na sede do município de Cajueiro da Praia tem uma base do Projeto Peixe-Boi Marinho, de responsabilidade do Centro de Mamíferos Aquáticos - CMA e do ICMBio. Foi o primeiro município brasileiro a receber o título de Patrimônio Natural do Peixe-Boi Marinho, através de uma lei municipal de 2003 (NETO, 2006). Assim, a prefeitura local é responsável, perante a lei, de proteger os sirênios (peixes-bois) e seus habitats (estuários, rios e mar), além de poder explorar este título para incrementar a atividade turística e articular parcerias com entidades para preservar este mamífero. Esta atividade de turismo de observação ainda está iniciando na localidade, que só possui três pousadas, de caráter familiar.

No povoado Barra Grande, até julho de 2009, existiam nove pousadas, algumas com padrão internacional e uma boa estrutura de bares e restaurantes na sua praia principal. Existem duas associações de condutores de visitantes que realizam passeios ecológicos em trilhas e canoas, com os turistas. O povoado é uma referência para praticantes de esportes aquáticos, como o kitesurf, que já atrai praticantes de vários Estados do país e exterior.

Os povoados de Barrinha e Morro Branco não possuem nenhum tipo de meio de hospedagem, mas têm várias praias desertas e de beleza cênica singular, que se forem estruturadas podem atrair muitos turistas, movimento a economia local.

\section{Metodologia}


Metodologicamente, nesta pesquisa foram aplicados dois tipos de formulários: um para turistas e outro para moradores locais. Os formulários destinados aos turistas investigaram dados como: idade, sexo, cidade onde mora, motivação da viagem, tempo de permanência e opinião sobre as localidades. Este formulário teve uma amostragem do tipo não probabilística por conveniência ou acidental, devido à população da pesquisa ser infinita, ou seja, desconhecida o número total de elementos do universo amostral.

Assim, a amostra foi calculada da seguinte forma: foram utilizados os únicos dados disponíveis sobre a demanda do município de Cajueiro da Praia, através do documento do PRODETUR/NE II (BNB, 2009), datado de 2001. Neste ano, registrou-se a presença de 1.941 turistas, em apenas quatro pousadas existentes, com um total de 31 Unidades Habitacionais UH's. Em seguida, compararam-se estes dados com os de Carvalho (2008), com pesquisa em 2007, verificando-se aumento do número total de UH's em 113\%. Em relação ao número de turistas, não há dados atuais, mas a tendência é que este número também tenha aumentado, em decorrência do crescimento da oferta. Dessa forma, definiu-se que houve o mesmo aumento em número de turistas, ou seja, estimou-se que, em 2007, estiveram no município cerca de 4.134 turistas.

Deste modo, depois de definido a possível população da pesquisa, utilizou-se do programa Raosoft (2009) para calcular a quantidade de formulários que seriam aplicados, com uma margem de erro de $8 \%$ e nível de confiança de $90 \%$, totalizando 104 formulários. Estes foram aplicados aos turistas que estavam em pousadas do município, selecionando aproximadamente $30 \%$ da demanda de cada estabelecimento hoteleiro no dia da pesquisa. Os formulários foram aplicados em três períodos diferentes, no ano de 2009.

Os formulários destinados à comunidade local identificaram a percepção que os moradores têm da atividade turística no povoado onde vivem, enfocando seus pontos positivos e negativos e a sua participação no processo de desenvolvimento do turismo local. Estes formulários foram analisados separadamente, pois os moradores do povoado Barra Grande, por terem um contato maior com o turismo, já sentem os seus efeitos, enquanto os moradores da sede municipal e outros povoados ainda não viveciam a atividade rotineiramente; expressaram opiniões sobre os seus impactos e conseqüências no futuro. 
Desta forma, utilizou-se o mesmo programa, Raosoft, para delimitar as amostras que são proporcionais ao número de famílias de cada povoado, a partir de dados do PSF. Assim foram aplicados 26 formulários no povoado Barra Grande; 11 no povoado Barrinha; 13 no povoado Morro Branco e 48 na sede municipal.

\section{Percepção dos Turistas}

Nesta pesquisa consideraram-se como "turistas" apenas os visitantes que estiveram hospedados em alguma pousada do município. Assim, dos pesquisados, 73\% estavam hospedados no povoado Barra Grande, e o restante, 27\% estavam hospedados na sede municipal. Destes, $57 \%$ são do sexo feminino, enquanto $43 \%$ são do sexo masculino. Em relação à idade, $56 \%$ têm entre 20 a 39 anos, 22\% entre 40 a 49 anos, $13 \%$ entre 50 a 59 anos, e $10 \%$ acima de 60 anos.

Percebeu-se, então que 78\% dos turistas são jovens, com idade entre 20 a 49 anos. Este dado pode estar relacionado aos períodos em que os formulários foram aplicados: carnaval, semana-santa e férias escolares no mês de julho; além da própria característica do município, que atrai jovens para a prática de esportes. Percebeu-se, também, que a grande maioria dos turistas estavam hospedados no povoado Barra Grande, devido este ter o maior número de pousadas, e por esta localidade ter sido a primeira do município a ser "descoberta" pelos turistas.

A pesquisa revelou que $100 \%$ dos turistas chegaram ao município por meio de automóvel, enquanto nenhum dos pesquisados afirmou ter tido ônibus de linha regular ou fretado como meio de transporte. Em relação à cidade onde moram, 58\% dos turistas responderam que residem em Teresina - PI e 12\% em Parnaíba - PI, significando que a grande maioria dos visitantes do município é do próprio Estado, enquanto outros $10 \%$ moram em Fortaleza - CE, 7\% em São Luis - MA, 6\% em São Paulo - SP, e outros 7\% residem em outras cidades.

Esta grande presença de teresinenses nas localidades se deve a um fator cultural. É costume viajarem para o litoral piauiense no período de férias e feriados, por ser a região de litoral nordestino mais próxima da capital do Estado, a $400 \mathrm{~km}$. As pequenas distâncias entre as 
cidades de Parnaíba - PI (72 km), Fortaleza - CE (a $565 \mathrm{~km})$ e São Luis - MA $(555 \mathrm{~km})$ à Cajueiro da Praia, também favoreceu a ida de turistas destas regiões para o município.

A maioria dos turistas pesquisados, $84 \%$, afirmou que soube do povoado/município a partir de amigos e/ou parentes, enquanto apenas 9\% souberam por meio da mídia, e outros 7\% souberam do local por outras formas. Nenhum dos pesquisados soube do local através de informações obtidas na Internet, revistas e guias turísticos especializados ou folders informativos. Deste modo, a maior divulgação do povoado/município acontece pelo chamado "boca-a-boca". Entende-se, então, que há falta de divulgação e informação turística sobre município nas regiões emissoras, principalmente no próprio Estado, onde reside a maior parte dos turistas. Isto seria uma limitação para o desenvolvimento turístico local, pois um destino turístico que não é bastante conhecido e divulgado não pode atrair muitos visitantes.

Desde o início do desenvolvimento turístico do município de Cajueiro da Praia, a principal motivação das viagens ao local era a busca pela tranqüilidade que o município passava. Os turistas se deslocavam para o município a fim de "fugir" das festas e badalações que o município vizinho, Luís Correia, oferecia. Assim, esta motivação continua sendo a principal, para $52 \%$ dos turistas pesquisados, enquanto $16 \%$ apontaram as praias, $14 \%$ a curiosidade/novidade, $9 \%$ a prática de esportes, $9 \%$ por outros motivos.

Notou-se que a prática de esportes teve uma participação significativa nos dados coletados, apesar da pesquisa ter sido realizada em períodos em que a força e intensidade dos ventos não estivessem em condições ideais para a prática de esportes náuticos, como o kitesurf. O melhor período para a prática deste e outros esportes que necessitam de ventos, é entre os meses de agosto a outubro. Nestes meses, a velocidade do vento é alta, atraindo visitantes de várias regiões do país, inclusive estrangeiros.

Em relação ao tempo de permanência dos turistas, em Cajueiro da Praia, 47\% dos pesquisados ficaram no município por 4 dias ou mais, outros $42 \%$ permaneceram por 3 dias, e outros $10 \%$ por 2 dias, enquanto apenas 1\% ficou apenas um dia. Isto mostra que a maioria dos seus visitantes, $52 \%$, permaneceram de 2 a 3 dias no município. Este dado pode estar relacionado ao período de aplicação dos questionários (carnaval e semana santa) e indicam que o visitante não está de férias, mas apenas aproveitando esses poucos dias de feriados. Outra razão para 
essa reduzida permanência pode estar relacionada à própria infraestrutura do município que não dispõe de muitas opções de lazer. Assim, o oferecimento de opções variadas de lazer diurno e noturno poderia aumentar este tempo de permanência, possibilitando dessa forma uma maior geração de renda para moradores locais.

Os turistas foram questionados sobre a quantidade de vezes que visitaram o município, e 39\% responderam que já visitaram o município de Cajueiro da Praia de 2 a 3 vezes, outros 35\% estavam conhecendo pela $1^{\mathrm{a}}$ vez, e outros $26 \%$ já haviam visitado o local mais de 3 vezes. Os dados mostram que a maioria dos turistas pesquisados $(65 \%)$ já retornou ao município, pelo menos uma segunda vez, comprovando que gostaram do local.

Os pesquisados, também, tiveram que classificar alguns itens sobre o município entre ótimo, bom, regular ou péssimo. Em relação às informações turísticas, que seriam informações prestadas aos turistas sobre os eventos que ocorrem no município, os atrativos turísticos, a infraestrutura, serviços e acessos, $44 \%$ dos pesquisados acharam regular, $30 \%$ péssimo e $23 \%$ bom, enquanto 3\% não souberam responder e ninguém achou ótimo (Gráfico 1). Este é um dado importante, já que no povoado Barra Grande há um posto de informações turísticas, porém, sem horários definidos de funcionamento.

Em relação à sinalização turística, que fornece informações sobre atrativos e destinos turísticos, $45 \%$ dos pesquisados acharam regular, 32\% bom e 23\% péssimo (Gráfico 1). Partindo de Luís Correia até chegar ao município, existem algumas placas de sinalização turística, porém com informações erradas, principalmente no que se refere às distâncias. Entretanto, sobre a sinalização de trânsito, que informa e orienta os condutores de veículos sobre as vias, $38 \%$ dos turistas pesquisados acharam que é boa, enquanto $32 \%$ acharam regular, $27 \%$ acharam péssima e 3\% não responderam (Gráfico 1).

A hospitalidade está relacionada com a qualidade de um indivíduo ou comunidade de receber bem e acolher. Entretanto, para Campos (2006, p. 4) "o ato de hospedar e ser hospitaleiro são muito mais complexos que simplesmente receber o visitante; consiste na união, ou melhor, na aproximação de culturas, costumes e pessoas diferentes. Trata-se de uma relação de troca de valores entre o visitado e visitante". Segundo Bedim e Paula (2007, p. 72), a hospitalidade pode "influenciar não apenas a imagem que o turista forma do destino, como também pode se 
configurar como fator determinante do tempo de permanência do turista na localidade e, por conseguinte, dos seus gastos". Assim, quanto à hospitalidade dos moradores de Cajueiro da Praia, a grande maioria dos pesquisados (62\%) afirmou ser ótima, 27\% acharam boa, enquanto $6 \%$ acharam regular e $5 \%$ péssima (Gráfico 1). Deste modo, a hospitalidade é um fator positivo para atração de visitantes e da sua permanência no município, como mostrado anteriormente, onde $47 \%$ dos pesquisados permaneceram por 4 dias ou mais.

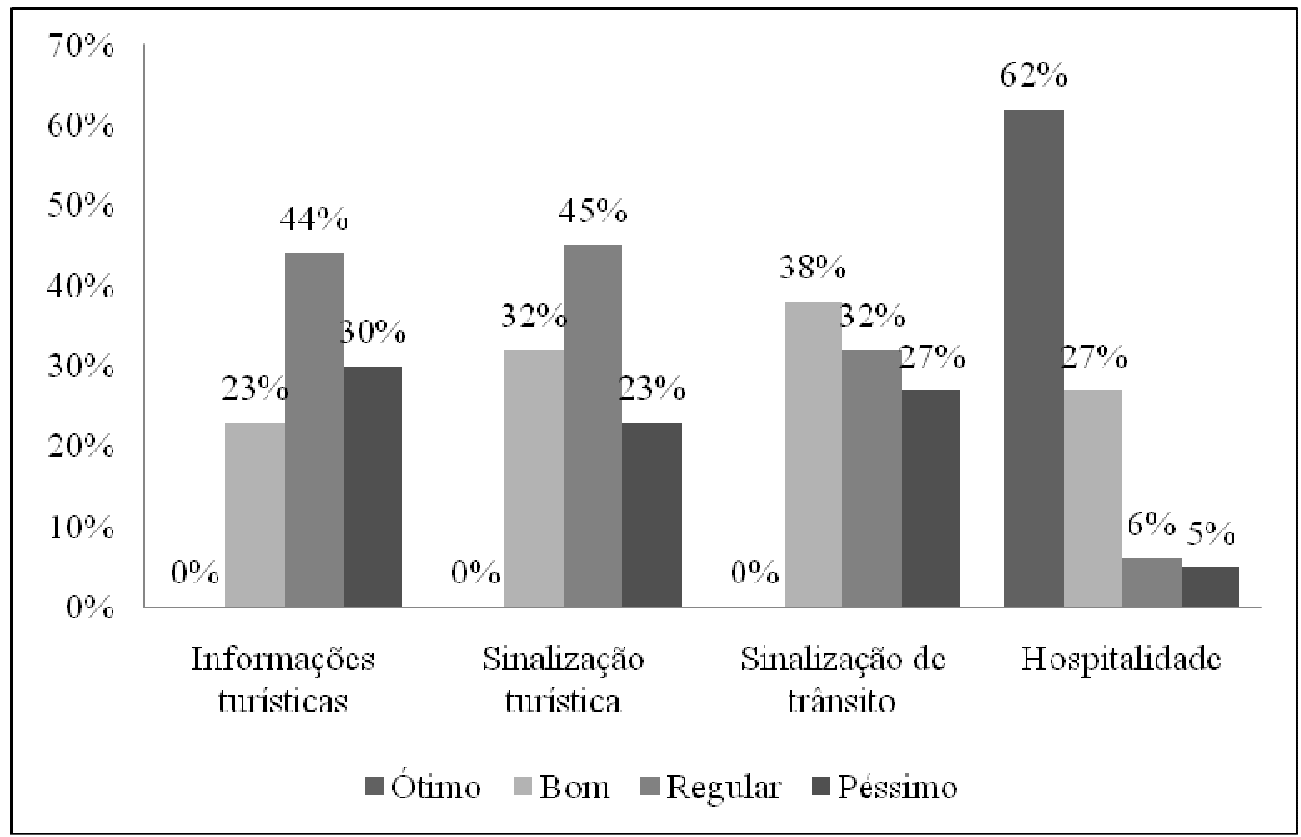

Gráfico 1 - Distribuição percentual de turistas, em Cajueiro da Praia - PI, segundo a opinião sobre o município (I)

Fonte: Pesquisa direta, fev.- jul./2009

Sobre a limpeza das praias, $58 \%$ dos turistas a consideram boa e $9 \%$ ótima, apesar de reclamarem da grande presença de algas marinhas na orla que lhes incomodavam, enquanto $25 \%$ acharam regular e $8 \%$ péssima. Este inconveniente poderia ser resolvido se as algas fossem retiradas das praias e utilizadas por indústrias de cosméticos, com a fabricação de xampus, cremes e outros produtos de beleza, aproveitando a mão-de-obra local. Desta forma, outra alternativa de emprego e renda para a comunidade seria gerada além de melhorar o aspecto estético das praias. 
Em relação à limpeza urbana, 57\% acharam boa, 37\% regular, 3\% péssima, e outros 3\% não souberam responder (Gráfico 2). Foi constatado que no município há poucas lixeiras, assim, o lixo é jogado, em vários locais, a céu aberto, o que provoca mau cheiro e atrai animais.

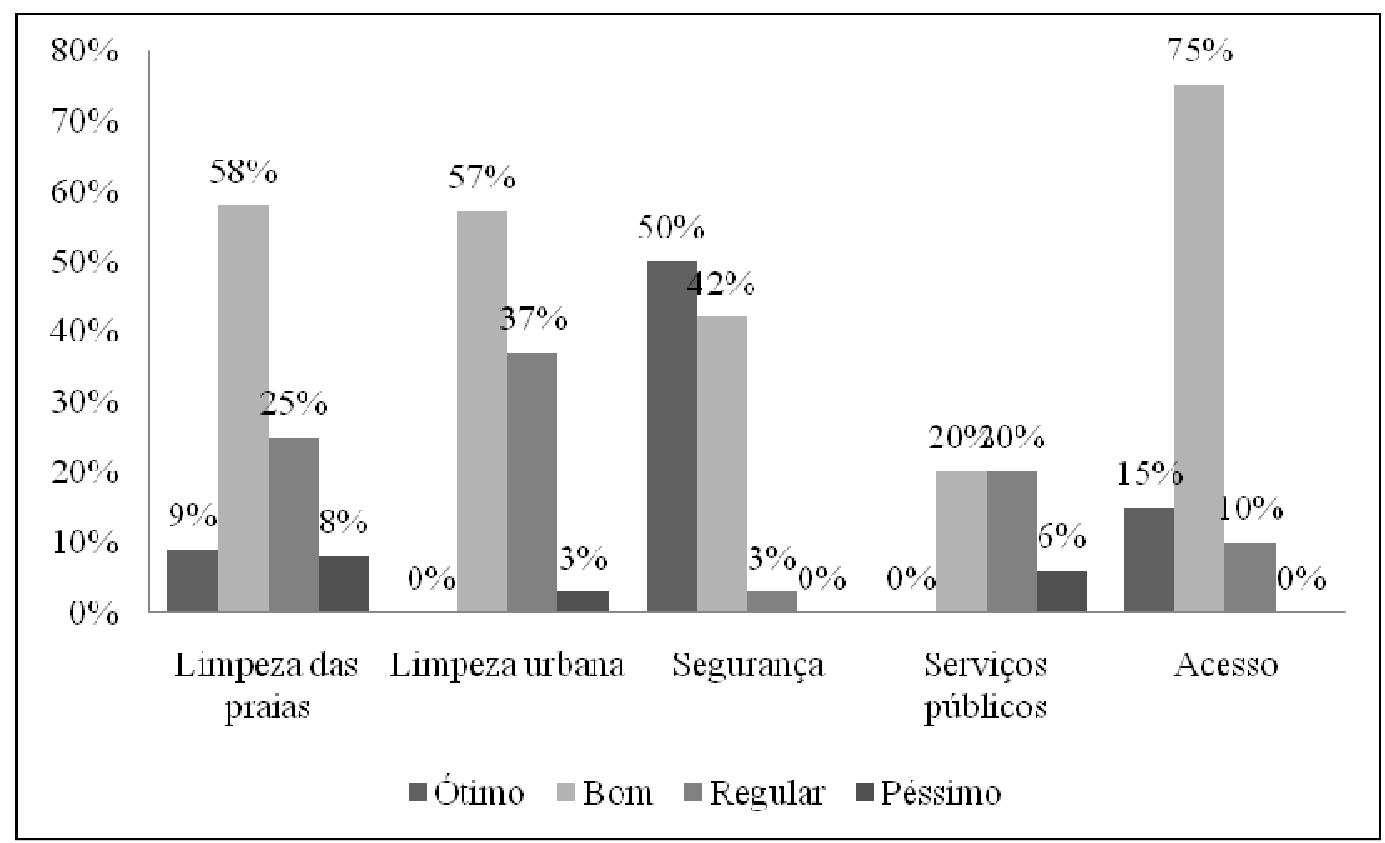

Gráfico 2 - Distribuição percentual de turistas, em Cajueiro da Praia - PI, segundo a opinião sobre o município (II)

Fonte: Pesquisa direta, fev.- jul./2009

O município de Cajueiro da Praia passa a seus visitantes a imagem de ambiente tranquilo e seguro, mesmo não existindo policiamento ostensivo nas ruas. Por este motivo, $50 \%$ dos turistas consideram a segurança ótima e $42 \%$ a consideram boa, enquanto $3 \%$ a acham regular e 5\% não souberam responder (Gráfico 2). Este dado é importante, pois, atualmente, a segurança tem sido um critério na busca de destinos turísticos. Segundo Ferri et al. (2001), ao se falar em segurança deve-se pensar em todos os seus níveis, como terrorismo, guerra e criminalidade, como também a falta de fiscalização e o não cumprimento de leis e normas. Os autores destacam, ainda, que a maioria dos prestadores se serviços turísticos não está preparada para agir em situações de emergência. Naisbitt (1999, p.158) afirma que "a preocupação com a segurança pessoal e com os haveres transportados exerce um nítido 
impacto na escolha da destinação". Assim, os turistas procuram visitar locais seguros, e é o que está acontecendo em Cajueiro da Praia, sendo mais um fator positivo para o desenvolvimento turístico local.

Em relação aos serviços públicos, a maioria dos turistas pesquisados (54\%) não precisou destes serviços, portanto não soube responder, enquanto $20 \%$ afirmaram serem bons, outros $20 \%$ afirmaram serem regulares e outros $6 \%$ acharam péssimos. E em relação ao acesso rodoviário, que na sua maior parte estava com uma pavimentação asfáltica em boas condições, $75 \%$ dos turistas o acharam bom, 15\% o acharam ótimo, e apenas $10 \%$ o acharam regular (Gráfico 2). Porém, 27\% dos turistas reclamaram da presença de animais na pista, que é um perigo.

Os turistas, quando questionados se pretendiam voltar ao município de Cajueiro da Praia, tiveram um consenso: $100 \%$ disseram que voltariam. Isto mostra que, apesar de alguns itens sobre o município não terem índices satisfatórios, como a sinalização e informação turísticas, os turistas gostaram de Cajueiro da Praia e pretendem voltar em outras oportunidades. Assim, o desenvolvimento do turismo local tende a ser contínuo.

\section{Percepção dos Moradores sobre a Atividade Turística}

\subsection{Percepção dos moradores do povoado Barra Grande}

Em Barra Grande foram aplicados 26 formulários a moradores com idade superior a 19 anos, em diversos pontos da localidade. Destes, 59\% são do sexo feminino e $41 \%$ do sexo masculino. Em relação à idade, 55\% têm entre 20 a 39 anos, 14\% entre 40 a 49 anos, 22\% entre 50 a 59 anos, e 9\% têm acima de 60 anos. Os dados mostraram que a maioria dos moradores do povoado são mulheres jovens, que poderiam ser utilizadas como mão-de-obra em empreendimentos turísticos locais.

Quando questionados se aceitam que o turismo seja desenvolvido no município, a grande maioria (97\%) afirmou que sim, enquanto 3\% disseram que não. A aceitação, por parte dos moradores locais, do desenvolvimento da atividade turística é fundamental, pois isto influencia diretamente no tratamento dado aos visitantes. 
Magalhães (2002) afirma que à medida que a comunidade vai se sentindo envolvida, torna-se mais motivada em relação a sua participação no processo de desenvolvimento do turismo, o que pode levar ao surgimento do senso de responsabilidade de ser guardiã dos patrimônios natural, histórico e cultural da localidade. Neste processo, a comunidade também tem um papel importante de fiscalizador da atividade e avaliador dos reais impactos sentidos pela população local e quais as mudanças seriam melhor aproveitadas por ela. Assim, os residentes discutem o que querem e o que podem fazer para contribuir para o desenvolvimento local.

Neste sentido, sobre a relação que os moradores têm com o turismo, 56\% afirmaram ter algum tipo de relação com a atividade, enquanto $44 \%$ não. Dos que têm relação com o turismo, $53 \%$ têm uma relação direta, ou seja, trabalham em alguma atividade desenvolvida exclusivamente para o turismo, como por exemplo, em pousadas. Enquanto $47 \%$ têm uma relação indireta, ou seja, trabalham em atividades feitas para a comunidade local, das quais o turismo pode se apropriar, como é o caso da pesca.

Estes dados mostram a influencia do turismo na renda dos moradores do povoado Barra Grande, com a geração de empregos. Contudo, no turismo, a geração de renda pode se restringir a poucos, e os empregos gerados podem não absorver a mão-de-obra local, por falta de qualificação adequada que os trabalhos exigem. Neste sentido, o poder público local tem que intervir para promover, à comunidade, recursos e treinamentos que lhes são necessários.

Os moradores que não têm relação com a atividade turística foram indagados se gostariam de trabalhar em alguma atividade relacionada ao turismo. Os dados indicaram que 59\% disseram que sim, enquanto $41 \%$ disseram não ter interesse. Este número pode estar relacionado com a idade dos moradores pesquisados, uma vez que são em sua maioria jovens, e estão em busca de emprego ou de um trabalho melhor do que o turismo poderia proporcionar.

Como os moradores de Barra Grande já têm contato com a atividade turística, perguntou-se quais os principais benefícios que o turismo proporcionou para o povoado. Os resultados indicaram que $32 \%$ acharam que houve um aumento da oferta de serviços, $27 \%$ acreditaram que houve um aumento de empregos e renda, $18 \%$ indicaram uma melhoria na infraestrutura de acesso, 17\% acharam que houve uma maior divulgação do município, e 6\% apontaram uma melhoria do saneamento básico (Gráfico 3). 


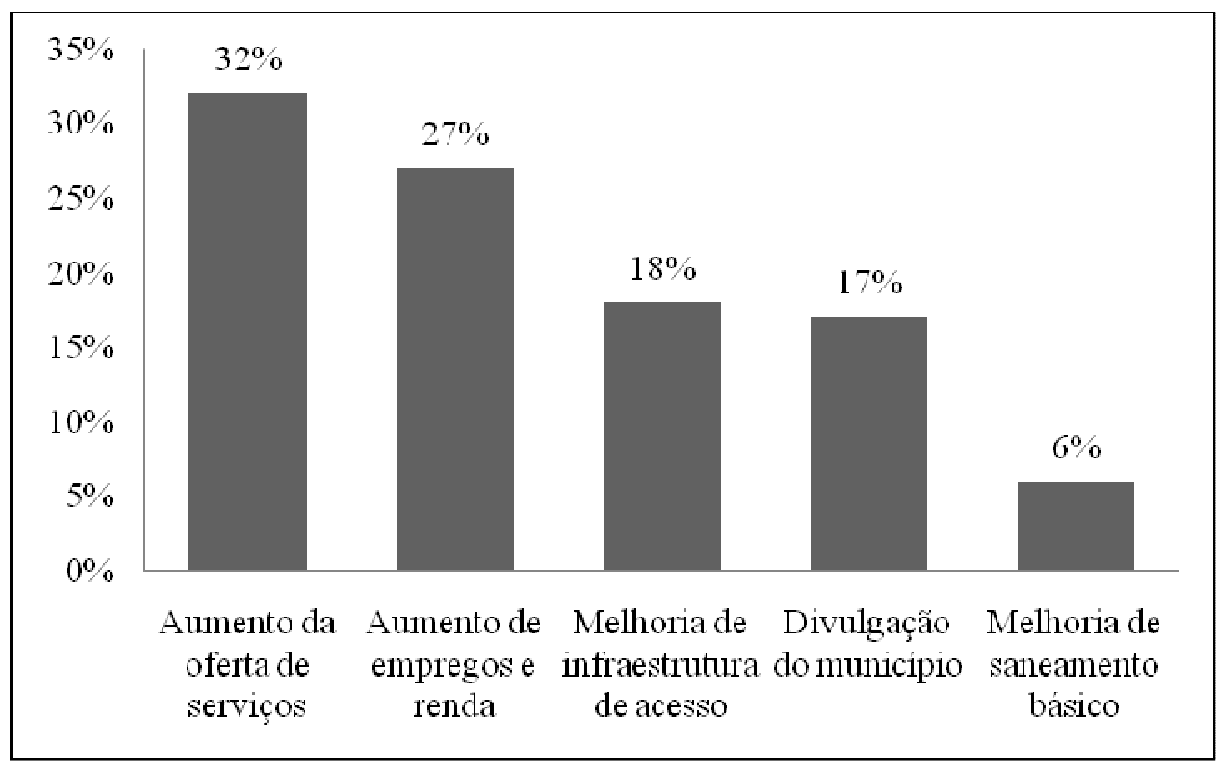

Gráfico 3 - Distribuição percentual dos moradores do povoado Barra Grande, segundo os benefícios proporcionados pelo turismo local - Cajueiro da Praia - PI Fonte: Pesquisa direta, jul./2009

Em relação a impactos negativos do turismo, 90\% dos pesquisados afirmaram que a atividade turística local trouxe efeitos negativos para o município, enquanto $5 \%$ disseram que não, e outros 5\% não souberam responder. Assim, 42\% dos pesquisados afirmaram que houve especulação imobiliária e elevação dos preços de produtos e serviços, 30\% apontaram poluição de praias, rios e lagoas, 14\% apontaram poluição sonora, 11\% apontaram destruição da vegetação local, e 16\% citaram outros impactos negativos, como o aumento da violência e do consumo de drogas (Gráfico 4). 


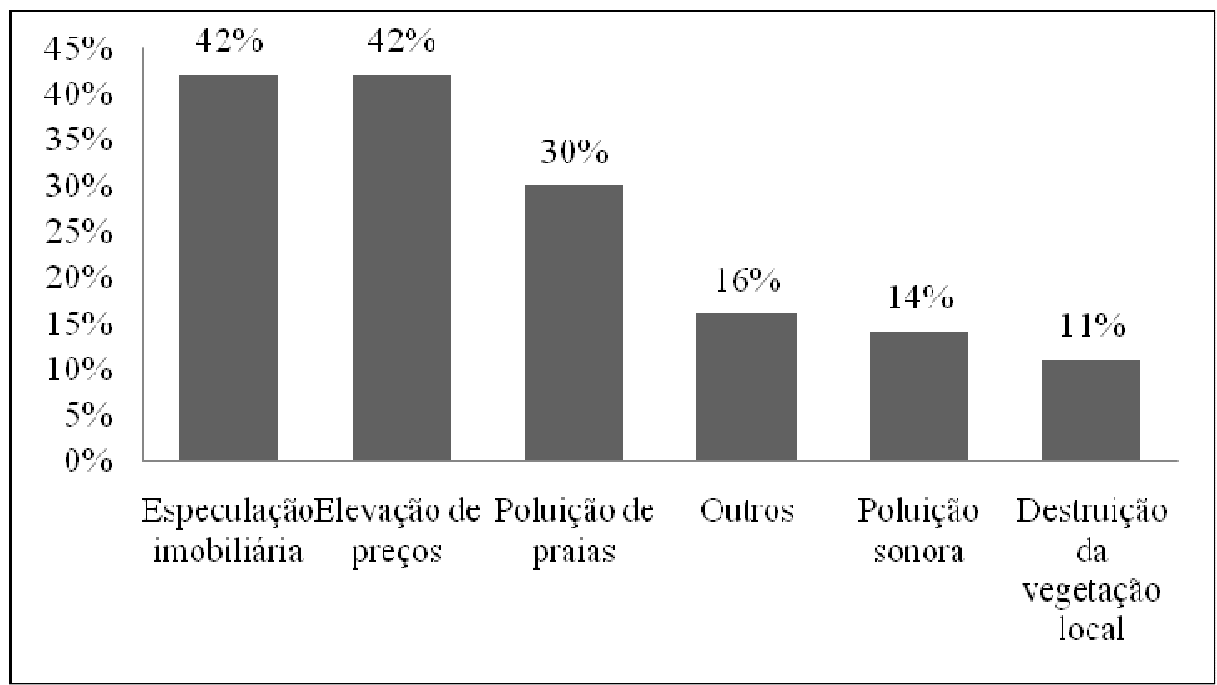

Gráfico 4 - Distribuição percentual dos moradores do povoado Barra Grande segundo a percepção dos impactos negativos provocados pelo turismo - Cajueiro da Praia - PI Fonte: Pesquisa direta, jul./2009

Apesar de considerarem que o turismo local provocou impactos negativos, $83 \%$ dos moradores pesquisados disseram que a atividade provoca mais efeitos positivos do que negativos, enquanto $12 \%$ não concordam com isso, e 5\% não souberam responder. Estes resultados mostraram que a comunidade do povoado Barra Grande tem uma consciência dos principais impactos que o turismo tem ocasionado na localidade.

Monteiro e Monteiro (2008, p. 4) comentam que:

os moradores devem possuir um olhar crítico para a prática do turismo, percebendo que este poderá valorizar seus patrimônios culturais, naturais e ainda gerar renda na comunidade com a venda do artesanato, divulgação da gastronomia local, etc. É necessário ressaltar que a relação entre moradores e turistas deve ser harmônica e se caracteriza por ser nutrida de interesses de ambas as partes.

Desta forma, este olhar crítico tem grande importância para o desenvolvimento turístico local, pois as comunidades podem desempenhar uma forte influência em qualquer processo de 
mudança que ocorra nas suas localidades, como o processo de desenvolvimento do turismo. Conforme Swarbrooke (2000, p.65):

as comunidades [podem ter] o controle total da política estratégica e das decisões táticas em relação ao turismo na área; as comunidades [podem ter] poder de veto contra todas as políticas e decisões sobre turismo que estejam nas mãos das entidades do setor público; as comunidades [podem estabelecer] as prioridades e os parâmetros da política e/ ou das decisões do setor público; às comunidades é permitido escolher uma política ou estratégia entre um pequeno numero de opções, todas as quais foram geradas pelos que elaboram as políticas do setor publico; as opiniões da comunidade são utilizadas para ajudar a justificar as decisões tomadas pelos órgãos do setor público; a comunidade [pode ser] consultada, mas os seus pontos de vista [podem não influenciar] significativamente a política do setor público.

Assim, para o autor o poder público tem conhecimento da influência que as comunidades devem ter, mas nem sempre dá importância a isto ou ao que elas pensam. Assim, promover o desenvolvimento local requer uma comunidade consciente e participativa, em todo o processo, desde o planejamento até a execução das ações.

Ghon (2003 apud IRVING; MENDOÇA, 2004) explica que participar significa dividir as responsabilidades na construção coletiva de um processo, que tem como objetivo fortalecer a sociedade civil para a construção de caminhos que apontem para uma nova realidade social, sem injustiças, exclusões e desigualdades.

Sobre as principais potencialidades turísticas no povoado, $100 \%$ dos moradores afirmaram que são as belezas das praias, rios e lagoas, $65 \%$ tranqüilidade e descanso, $44 \%$ os passeios, e $12 \%$ os eventos esportivos. Os resultados mostraram que as belezas naturais do povoado Barra Grande são os principais atrativos turísticos da localidade. Por este motivo, os moradores devem ter uma maior preocupação com a preservação dos mesmos, já que a qualidade ambiental é um fator importante para atração de turistas.

Em relação às limitações para o desenvolvimento turístico local, 79\% apontaram as precárias infraestrutura urbana e turística, 65\% citaram a inexistência de alguns serviços urbanos, como farmácia e posto de gasolina, $29 \%$ apontaram a falta de treinamento e qualificação para atender os turistas, $12 \%$ citaram a dificuldade de acesso, e outros $12 \%$ outros motivos. Para os 
moradores, a infraestrutura urbana do município precisa melhorar bastante, pois os sistemas de abastecimento de água, luz, telefone e telefonia móvel ainda são insuficientes e precários. Quanto à infraestrutura turística, segundo os moradores, há a necessidade de integração dos empreendimentos turísticos com a comunidade, tanto com a possibilidade de utilização da estrutura física destes estabelecimentos por parte dos moradores, como pela oferta de empregos neste setor; além da implantação e melhoria de alguns serviços, como agências de viagens e transporte turístico.

\subsection{Percepção dos moradores da sede municipal e dos outros povoados da orla marítima}

Na sede municipal foram aplicados 48 formulários, no povoado Barrinha foram aplicados 11, e no povoado Morro Branco foram aplicados 13, totalizando 72 formulários. Dos moradores pesquisados, $54 \%$ são do sexo feminino e $46 \%$ do sexo masculino. Em relação à idade, 54\% têm entre 20 a 39 anos, $13 \%$ entre 40 a 49 anos, 10\% entre 50 a 59 anos, e $23 \%$ têm acima de 60 anos. Os dados obtidos revelam que a maioria dos moradores da sede municipal e dos outros povoados da orla marítima são mulheres jovens, assim como no povoado Barra Grande. Entretanto, há um número significativo de idosos, uma vez que o município se originou a partir de uma vila de pescadores, na área onde está localizada a sede municipal.

Quando questionados se eles aceitam que o turismo seja desenvolvido no município, a grande maioria (93\%) respondeu que sim, enquanto 7\% disseram que não. A aceitação é um dado importante, pois se a comunidade local não aceitar que a atividade turística seja desenvolvida, ele estará fadado ao fracasso. Porém, esta aceitação é também preocupante, pois percebeu-se que os moradores da sede municipal e dos outros povoados da orla marítima não têm muita consciência do que é o turismo e de quais são os seus reais impactos. Para eles, o turismo seria o "salvador do mundo".

Isto é comprovado quando questionados sobre os possíveis impactos negativos que o turismo pode provocar no município, já que nessas localidades os moradores ainda não vivenciam a atividade turística no seu dia-a-dia, como acontece no povoado Barra Grande. Os dados mostraram que para $53 \%$ dos pesquisados a atividade turística pode trazer efeitos negativos para o município, enquanto para $28 \%$ não, e outros $19 \%$ não souberam responder. Assim, para um número significativo de moradores, o desenvolvimento do turismo só traria conseqüências 
positivas, o que não acontece na realidade, mostrando que eles têm uma imagem distorcida da atividade turística. E segundo diversos autores, como Barretto (1995), Ruschmann (1997) e Dias (2005), o turismo provoca tanto efeitos positivos quanto negativos.

Dentre os moradores que afirmaram haver efeitos negativos, 35\% dos moradores afirmaram que pode ocorrer especulação imobiliária, 29\% apontam elevação dos preços de produtos e serviços, $22 \%$ citaram poluição de praias, rios e lagoas, $12 \%$ apontaram destruição da vegetação local, $6 \%$ poluição sonora e $13 \%$ citaram outros impactos negativos, como o aumento da violência, do consumo de drogas e a chegada de costumes ruins (Gráfico 5).

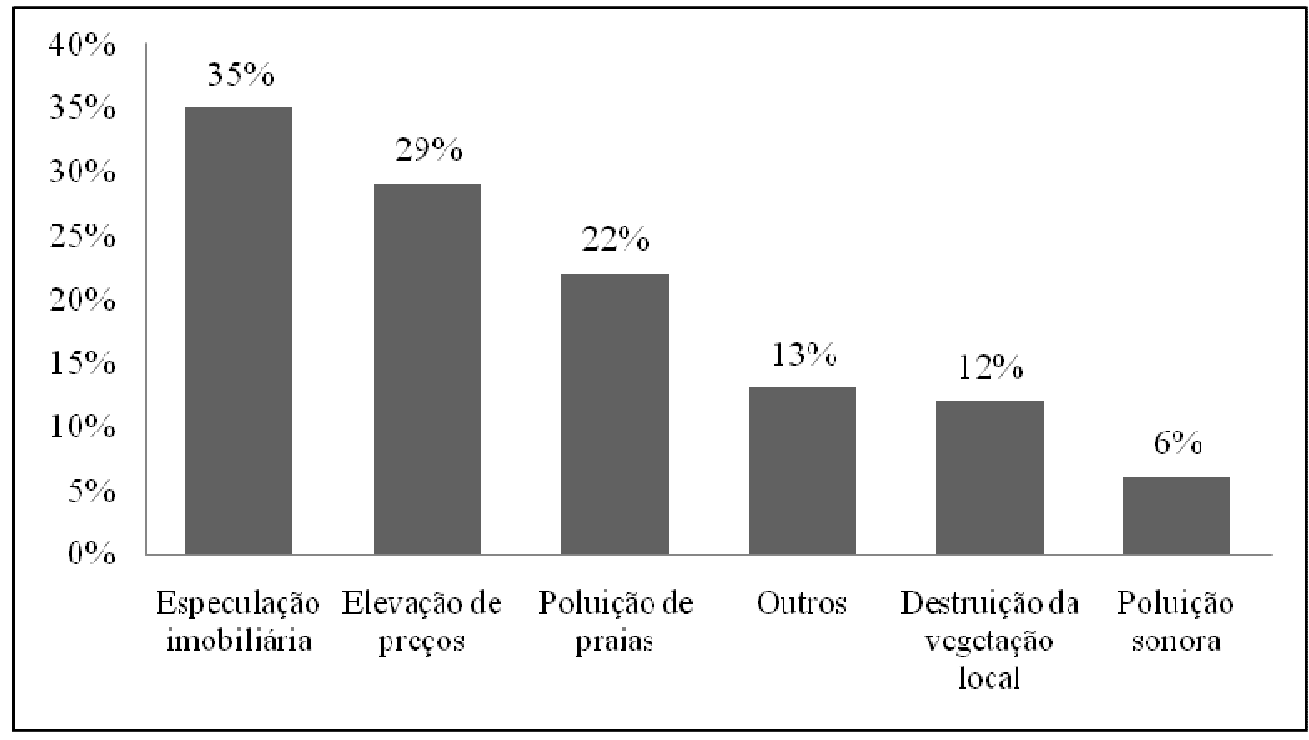

Gráfico 5 - Distribuição percentual dos moradores da sede municipal e dos outros povoados da orla marítima, segundo a percepção dos possíveis impactos negativos que o turismo pode proporcionar ao município - Cajueiro da Praia - PI

Fonte: Pesquisa direta, jul./2009

Os moradores foram indagados sobre quais seriam os benefícios que o turismo poderia trazer ao município, com o desenvolvimento da atividade. Os dados mostraram que $92 \%$ achavam que pode haver um aumento de empregos e renda, 77\% esperam um aumento da oferta de serviços, $73 \%$ uma melhoria na infraestrutura de acesso, $33 \%$ prevêem uma maior divulgação 
do município, $24 \%$ esperam uma melhoria do saneamento básico, e $6 \%$ não souberam responder (Gráfico 6). Os dados revelaram que 98\% dos moradores disseram que o turismo pode provocar, assim, mais impactos positivos do que negativos, e apenas $2 \%$ dos moradores pensam ao contrário.

A porcentagem destes números é alta, comparadas com as do povoado Barra Grande, onde $32 \%$ dos moradores acharam que houve um aumento da oferta de serviços, $27 \%$ acreditavam que houve um aumento de empregos e renda, 18\% identificaram uma melhoria na infraestrutura de acesso, 17\% achavam que houve uma maior divulgação do município, e 6\% viram uma melhoria do saneamento básico. Isto confirma que para os moradores das outras localidades da orla marítima do município de Cajueiro da Praia o turismo é a grande esperança de melhorar a qualidade de vida local.

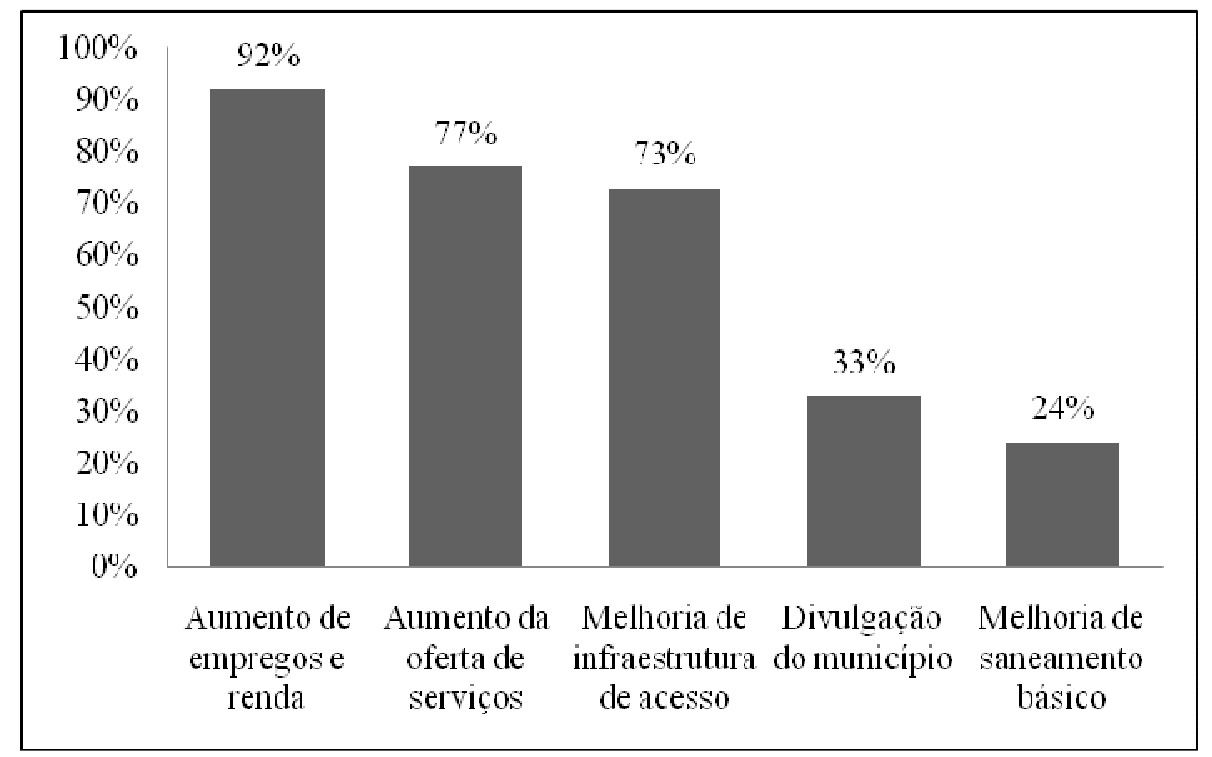

Gráfico 6 - Distribuição percentual dos moradores da sede municipal e dos outros povoados da orla marítima, segundo percepção dos possíveis benefícios que o turismo pode proporcionar ao município - Cajueiro da Praia - PI

Fonte: Pesquisa direta, jul./2009 
Sobre a relação que os moradores têm com o turismo, 36\% afirmaram ter algum tipo de relação com a atividade, enquanto a maioria (64\%) respondeu que não tem. Dos que têm relação com o turismo, $21 \%$ têm relação direta, enquanto $79 \%$ têm uma relação indireta. Os dados comprovaram que os moradores da sede municipal e dos outros povoados da orla marítima ainda não sofrem uma influência significativa da atividade turística. A maioria das relações se dá de maneira indireta, ou seja, os moradores trabalham em atividades que não são exclusivas para o turismo, mas que podem ser apropriadas por ele.

Dos moradores que não têm relação com a atividade turística, $62 \%$ gostariam de trabalhar em alguma atividade relacionada ao turismo, enquanto 38\% disseram não ter interesse. Estes dados devem estar relacionados com a idade dos moradores, em sua maioria jovens, que podem ser aproveitados como mão-de-obra para atividades relacionadas ao turismo.

Sobre as potencialidades turísticas das localidades, $78 \%$ dos moradores citaram a beleza das praias, rios e lagoas, 64\% o Projeto Peixe-Boi Marinho (localizado na sede municipal), 31\% tranqüilidade e descanso, $13 \%$ os passeios, e 3\% os eventos esportivos. Os dados revelaram que, para a grande maioria dos moradores das localidades, o Projeto Peixe-Boi Marinho é uma atrativo turístico local importante, e que o desenvolvimento das atividades do mesmo, poderá incrementar a renda e gerar empregos para a comunidade local.

Em relação às limitações para o desenvolvimento turístico local, 77\% apontaram as precárias infraestruturas urbana e turística, assim como no povoado Barra Grande. Para 53\% seria a inexistência de alguns serviços urbanos, como posto de gasolina e farmácia, $47 \%$ a falta de treinamento e qualificação para atender os turistas, 19\% citaram a dificuldade de acesso, e outros $3 \%$ outros motivos. Em relação à dificuldade de acesso, é uma limitação somente para os próprios moradores, por não terem muitas opções de transporte a outros municípios ou pela falta de conhecimento das estradas de acesso ao município de Cajueiro da Praia, pois como comentado anteriormente, para $90 \%$ dos turistas o acesso é bom ou ótimo. 


\section{Considerações Finais}

O município de Cajueiro da Praia possui vários atrativos e potenciais turísticos. Destes, alguns já são explorados turisticamente, enquanto outros são apenas potenciais, que poderiam ser alternativas de emprego e renda para a comunidade local.

De acordo com esta pesquisa, ficou comprovado que o turismo está sendo mais desenvolvido no povoado Barra Grande, que foi a $1^{\mathrm{a}}$ localidade do município de Cajueiro da Praia a atrair visitantes, o que provocou um aumento da oferta de serviços no povoado, e conseqüentemente, a geração de empregos e renda. Porém, nesta localidade, o turismo já trouxe impactos negativos que foram percebidos pela maioria da população, e que se não forem tomadas medidas rápidas pode trazer provocar efeitos irreversíveis, prejudicando a continuidade do desenvolvimento turístico local. Entretanto, as comunidades das outras localidades da orla marítima, os povoados Barrinha e Morro Branco e a sede municipal, ainda não vivenciam o turismo no seu dia-a-dia, porém, querem que ele se desenvolva a qualquer custo, pois acreditam que o turismo é o "salvador do mundo" e só trará benefícios. Este dado é preocupante, pois a comunidade local pode ficar alheia ao desenvolvimento turístico, sendo excluída do processo e de seus efeitos positivos.

Sobre os turistas, percebeu-se que a grande maioria teve conhecimento do município por meio de amigos e parentes, de uma maneira informal, pois não há divulgação de Cajueiro da Praia nas localidades emissoras de turistas. Isto é uma limitação para o desenvolvimento do turismo local, pois se houvesse divulgação turística, provavelmente aumentaria a demanda, o que acarretaria um uso maior dos serviços e produtos turísticos do município, movimentando a economia local. Entretanto, apesar de alguns pontos terem sido considerados ruins pelos turistas, como limpeza das praias e sinalização turística, constatou-se que $100 \%$ dos pesquisados pretendem voltar ao município, o que é um ponto positivo para o mesmo.

Assim, com esta pesquisa foi compreendida a percepção dos moradores do município de Cajueiro da Praia, bem como dos turistas que o visitam. Deste modo, percebeu-se que boa parte dos moradores tem conhecimento do que é o turismo e seus impactos, e das potencialidades e limitações para o desenvolvimento turístico local. E em relação à percepção 
dos turistas sobre o município, percebeu-se que a sua impressão foi satisfatória, apesar de ainda necessitar de muitos investimentos para receber ainda melhor os seus visitantes.

\section{Referências}

BAPTISTA, E. M. de C. 2004. Caracterização e importância ecológica e econômica dos recifes da zona costeira do Estado do Piauí. Teresina: UFPI, 2004. 290 f. Dissertação (Mestrado). Programa Regional de Pós-Graduação em Desenvolvimento e Meio Ambiente da Universidade Federal do Piauí (PRODEMA/UFPI/TROPEN). Teresina.

BARRETTO, M. 1995. Manual de iniciação ao estudo do turismo. Campinas, SP: Papirus.

BEDIM, B. P.; PAULA, H. E. de.; 2007. "Relatos visitados": história oral e pesquisa em turismo e hospitalidade. Considerações teórico-metodológicas. Caderno Virtual de Turismo, v. 7, n. 1.

BNB. 2001. PRODETUR/NE - visão geral. Disponível em: <http://www.bnb.gov.br/Content/ aplicacao/prodetur/visao/gerados/prodetur_visao_geral.asp>. Acesso 03 Mar. 2009.

BRASIL. 2009. MTUR. Casos de sucesso: regionalização. Disponível em: <http://www.turismo. gov.br/turismo/noticias/acontece/detalhes/20090703.html>. Acesso 29 Jul. 2009.

CAMPOS, S. R.; 2006. Os cinco sentidos da hospitalidade. Revista Global Turismo, v.2. Disponível em: $\quad<$ http://www.periodicodeturismo.com.br/site/artigo/viewArtigo.php?codigo $=64 \&$ titulo $=\mathrm{OS} \% 20$ CINCO\%20SENTIDOS\%20DA\%20HOSPITALIDADE>. Acesso $30 \mathrm{Jul} .2009$.

CARVAlHO, S. M. S. 2008. O municipio de Cajueiro da Praia (PI): perspectivas de desenvolvimento turístico. Teresina: UESPI, 2008. 75 f. Monografia (Graduação). Universidade Estadual do Piauí, Curso de Turismo. Teresina.

CAVALCANTI, A. P. B. 2000. Impactos e condições ambientais da zona costeira do Estado do Piauí. Rio Claro (SP): UNESP, 353 f. Tese (Doutorado). Instituto de Geociências e Ciências Exatas, Departamento de Geografia, Universidade Estadual Paulista. Rio Claro(SP).

DIAS, R. 2005. Introdução ao Turismo. São Paulo: Atlas.

FERRI, C.; FREITAS, A. F. de; FRONZA F. L. 2001. Análise de aspectos de segurança físicopatrimonial e pessoal no empreendimento Ilha de Porto Belo. Turismo: Visão e Ação, ano 4, n. 9, p.127-135.

IRVING, M. A.; MENDONÇA. T. C. 2004. Turismo de Base Comunitária: a participação como prática no desenvolvimento de projetos no Brasil - Prainha do Canto Verde, Beberibe (CE). Caderno Virtual de Turismo, v. 4, n. 4.

MAGALHÃES, C. F. 2002. Diretrizes para o turismo sustentável em municípios. São Paulo: Roca.

MONTEIRO, J. de O.; MONTEIRO, J. de O. 2008. Turismo, comunidade e preservação: a importância de práticas sustentáveis na localidade de Barro do Furado. In: SEMINÁRIO INTERNACIONAL DE TURISMO SUSTENTÁVEL, 2., Fortaleza. Anais, Eixo 4. Fortaleza - CE: Instituto Terramar e Fórum em Defesa da Zona Costeira do Ceará, 2008. CD-ROM.

NAISBITT, J. 1999. Paradoxo global. São Paulo: Campus.

NETO, A. 2006. Luiz Correia \& Cajueiro da Praia: Executivo e Legislativo. Teresina: Edições Geração 70. 
OLIVEIRA, E. S. 2006. Percepção dos autóctones em relação à economia, meio ambiente e ao turismo em Ilhéus - BA. In: SEMINTUR, 4., Caxias do Sul, RS. Anais, GT 10. Caxias do Sul, RS: Universidade Caixas do Sul, CD-ROM.

PIAUÍ. 2009. GOVERNO DO ESTADO. Região Pólo Histórico-Cultural realiza seminário sobre turismo. Disponível em: <http://www.piaui.pi.gov.br/materia.php?id=34623>. Acesso 30 Jul. 2009.

PIAUÍ. 1996. Secretaria de Planejamento. Fundação CEPRO. Macrozoneamento costeiro do Estado do Piauí. Fundação CEPRO, Fundação Rio Parnaíba. Teresina.

RAOSOFT. 2009. Simple size calculator. Disponível em: < http://www.raosoft.com/samplesize.html $>$. Acesso 20 Jan. 2009.

RUSCHMANN, D. van de M. 1997. Turismo e planejamento sustentável: a proteção do meio ambiente. 13. ed. Campinas, SP: Papirus.

SWARBROOKE, J. 2000. Turismo sustentável: meio ambiente e economia. Tradução: Esther Eva Horovitz. v.2, 3. ed. São Paulo: Aleph.

Recebido em: 12/10/2009 (1 ${ }^{\mathrm{a}}$ versão) $27 / 08 / 2010$ ( $2^{\mathrm{a}}$ versão)

Aprovado em: 04/10/2010 